\title{
Network interactions for pharmaceutical market access: findings from an explorative research
}

\author{
Andrea Runfola \\ Department of Economics, University of Perugia, Perugia, Italy, and \\ Simone Guercini and Matilde Milanesi \\ Department of Economics and Management, University of Florence, Florence, Italy
}

\begin{abstract}
Purpose - The purpose of this paper is to investigate pharmaceutical market access (MA) and the interaction between the pharmaceutical company and other business and non-business actors (NBAs) involved in the MA of ethical drugs, to identify the main categories of actors, their role for MA and the content of the interaction, adopting an industrial marketing approach.

Design/methodology/approach - A qualitative interpretivist approach is adopted, with interviews as the primary data collection method: 36 interviews have been conducted with 16 key informants from the pharmaceutical industry.

Findings - The findings of this study reveal that (i) MA can be seen as a relational-driven activity with specific features owing to the highly regulated nature of the pharmaceutical industry, (ii) there is a multiplicity of business, and NBAs involved in the MA activities with whom pharmaceutical companies interact to acquire knowledge, legitimacy and make MA timely and effective, and (iii) the interaction with each category of actors has specific content.

Originality/value - This paper advances the debate on the marketing and management of pharmaceutical companies by emphasizing the importance of MA and the need to conceptualize it according to an industrial marketing perspective, revealing the interdependencies among actors for MA and the content of the interaction. It also contributes to the industrial marketing literature that has recently stressed the importance of NBAs as part of the extended business network of a company by identifying different categories of actors, their role in terms of knowledge and legitimization and the features and the trade-off of the extended business network in highly regulated markets.
\end{abstract}

Keywords Interaction, Pharmaceutical industry, Industrial marketing, Market access, Socio-political actors

Paper type Research paper

\section{Introduction}

Pharmaceutical companies' role in the global economy and global health is now more evident than ever owing to the COVID-19 pandemic. Pharmaceutical companies are currently the object of a worldwide daily debate, as the COVID-19 pandemic has clarified the importance of scientific research and the need for the availability of new drugs, such as vaccines (Rome and Avorn, 2020). Therefore, the market access (MA) of new drugs is more and more in the spotlight today. MA of new drugs refers to the pharmaceutical company's activities to obtain the authorization and negotiate the price/reimbursement mechanism to launch a new ethical drug (a drug that requires a medical prescription). Hence, MA represents a strategic moment for the possibility of diffusion of the new ethical drug. Therefore, it benefits pharmaceutical companies (the launch of a new drug and profitability), patients and the health-care system (availability of a new drug). Furthermore, as MA implies negotiating with the regulatory authorities on price and reimbursement, both the profitability

The current issue and full text archive of this journal is available on Emerald Insight at: https://www.emerald.com/insight/0885-8624.htm

Journal of Business \& Industrial Marketing 36/13 (2021) 174-186

Emerald Publishing Limited [ISSN 0885-8624] [DOI 10.1108/JBIM-07-2020-0371] of the pharmaceutical company and its economic sustainability and the sustainability of a national healthcare system depend on this (Guercini et al., 2020).

In this scenario, how can management and marketing scholars contribute? The academic literature has proposed a rich debate on the management of innovation in pharmaceutical companies, with a focus on new technological paradigms and the role of alliances and partnerships for new product development (Gambardella, 1992; Bianchi et al., 2011; Allarakhia and Walsh, 2011; Toole, 2012). However, although the pharmaceutical industry has been the object of constant attention by marketing and management scholars, how new drugs find access to the market, despite being an extremely relevant marketing topic, represents a neglected area of research remaining substantially unexplored in the

\footnotetext{
(C) Andrea Runfola, Simone Guercini and Matilde Milanesi. Published by Emerald Publishing Limited. This article is published under the Creative Commons Attribution (CC BY 4.0) licence. Anyone may reproduce, distribute, translate and create derivative works of this article (for both commercial and non-commercial purposes), subject to full attribution to the original publication and authors. The full terms of this licence may be seen at http://creativecommons.org/licences/by/4.0/legalcode
}

Received 31 July 2020

Revised 9 January 2021

19 February 2021

22 May 2021

13 July 2021

Accepted 15 July 2021 
marketing and management literature. Contributions in the academic debate are essentially attributable to the medicalscientific area. They mostly address MA by providing general indications concerning the country-system regulatory rules and procedures (Panteli et al., 2015; Oortwijn et al., 2017) and investigating access methods for drugs for specific diseases (Zannad et al., 2017; Maynou and Cairns, 2019).

The few contributions in the marketing and managerial literature have emphasized how pharmaceutical companies organize themselves and the activities they carry out for market MA (Schiavone and Simoni, 2019). It has been stressed the need to conceive MA not as a moment of mere negotiation between the pharmaceutical company and the regulatory authorities but rather as a wider process that sees the pharmaceutical company engaged in a network of relationships with other actors (Guercini et al., 2020). Conceiving MA according to a network view can contribute to increasing the value associated with the entry of a new drug, according to a win-win logic for all the actors involved. Such contribution hints at the fact that, along with business actors, a relevant role is played by non-business actors (NBAs), particularly the social ones, such as patients associations or citizens, to whom pharmaceutical companies may relate to acquiring knowledge and legitimation. However, the content of the interaction with NBAs for MA remains a substantially unexplored topic, which is the gap that this paper intends to fill. Dealing with the role of NBAs is relevant because of the overall effects that MA has for pharmaceutical companies and society. Moreover, considering the regulated nature of the industry, how to relate to NBAs represents a challenge for the pharmaceutical company and the source of a trade-off between the need to interact and the limits to interaction imposed by rules and regulations.

The paper investigates pharmaceutical MA of new ethical drugs and the interaction between the pharmaceutical company and other business and NBAs involved. The paper identifies the main categories of actors, their role for MA and the content of the interaction, adopting an industrial marketing approach. According to previous studies published by scholars from the Industrial Marketing and Purchasing (IMP) Group, such actors lie in the taxonomy of business and NBAs according to an "extended business network" conceptualization (Latifi, 2013; Thilenius et al., 2016), adopted by the present study, which refers to an enlargement of the company's business network to include relevant players of non-business nature.

More specifically, the paper intends to answer the following research questions:

RQ1. How does an industrial marketing perspective contribute to the understanding of MA?

RQ2. Who are the non-business actors with which the pharmaceutical company interacts to support MA, and how do they contribute to MA?

The findings of this study allow a threefold contribution as follows:

- the paper advances the debate on the marketing and management of pharmaceutical companies by emphasizing the importance of $\mathrm{MA}$ and the need to conceptualize it according to an industrial marketing perspective, revealing the interdependencies among actors for MA and the content of interaction;

- it posits the importance of a processual view of relationaldriven MA, according to which interaction with different business and NBAs occurs in different moments and helps to acquire legitimacy and overcome a mere price-driven MA conceptualization that is normally associated with highly regulated markets; and

- it contributes to the industrial marketing literature that has recently stressed the importance of NBAs as part of the extended business network of a company. It specifically considers different NBAs categories, their role in terms of knowledge and legitimization and the features and a trade-off of the extended business network in highly regulated markets.

From a methodological point of view, the paper presents the results of qualitative research, which includes 36 in-depth interviews with 16 key informants from the pharmaceutical industry. The empirical investigation focuses on MA in the Italian context. The interpretative approach followed in the research allows us to outline the main relationships with NBAs and how each relationship contributes to MA. The paper is structured as follows. Section 2 deals with previous studies on $\mathrm{MA}$, then the industrial marketing literature on NBAs is presented and discussed concerning MA. Next, the research methodology and the main empirical results are presented. The theoretical and managerial implications of this study are then addressed. The paper ends with the limits and directions of future research.

\section{Theoretical background}

2.1 Market access and industrial marketing perspective In a highly regulated market such as the pharmaceutical one (Ekelund and Persson, 2003; Schiavone and Simoni, 2019), the interaction between the pharmaceutical company and the institutional actors responsible for the marketing authorization[1], represents a potential detrimental ground of the economic dimension associated with the new drug as well as the timing of diffusion. In this context, MA implies that a pharmaceutical company gets access to register a new drug and receives market authorization to sell it on a specific market. However, MA involves other complex activities, including negotiating price and reimbursement mechanisms, especially in countries like Italy and other European markets, characterized by a universalistic health-care system.

Negotiation for MA affects the prices and reimbursement of new drugs, thus representing a dimension that strongly influences the pharmaceutical company's ability to make innovative efforts effective. Besides, the authorization procedures in different countries can be characterized by different moments that can slow down entry times. MA has also a strategic role for institutional actors, given that it affects the sustainability of the health systems, especially if they are characterized by being universalistic systems (Data and Mariani, 2015; Milanesi et al., 2020). As well highlighted by Koçkaya and Wertheimer (2016), MA does not refer only to market authorization but involves other activities, such as health technology assessment rather than pricing or formulary. 
Although this is a highly impactful activity on the profitability dimension linked to innovation and the overall economic sustainability of the pharmaceutical company (Milanesi et al., 2020), the pharmaceutical MA has received little attention in both managerial and industrial marketing literature.

MA has received almost exclusively attention within the medical-scientific academic debate. Several studies consider how to demonstrate the therapeutic efficacy of a new drug to negotiate the price and reimbursement mechanisms of the new drug. For example, in their study of 36 national health systems, Panteli et al. (2015) highlight how the authorization decisionmakers substantially assess the impacts of the new drug based on two main aspects, namely, a lower level of out-of-pocket payments and the patient health gain. It has also been discussed that MA cannot only be oriented towards the pricereimbursement mechanism but is necessarily linked to other activities, as confirmed, for example, by Kumar et al. (2014). In their conceptual contribution to MA in emerging markets, the authors highlight a shift from a price-based to a value-based approach (Kumar et al., 2014, p. 1). Thus, it is necessary to consider the interests of a series of actors, among which five categories are central, namely, payers, pharmacies, advocacy groups, physicians and key opinion leaders, government and regulatory agencies (Kumar et al., 2014). The contribution by Sendyona et al. (2016) acknowledges the relevance of MA and the paradigmatic change that assigns to relationships with other actors a central role by adopting a multi-perspective that includes the many actors involved in the process. The authors define MA as "the process that ensures the development and commercial availability of pharmaceutical products with appropriate value propositions, leading to their prescribing and successful uptake decisions by payers and patients with the ultimate goal of achieving profitability and best patient outcomes" (Sendyona et al., 2016, p. 2). Thus, many stakeholders come into play in the MA process, such as payers, prescribers and patients.

However, such an issue seems to have received little attention from both managerial and marketing literature. Few industrial marketing studies have dealt with MA features. Schiavone and Simoni (2019) deal with the diffusion of innovation in the pharmaceutical market and investigate the characteristics of the marketing approach of the pharmaceutical company concerning MA. The authors conclude that MA requires the setting up of a dedicated and specific organizational unit for a better performance of these activities. Moreover, they underline how, for more effective diffusion of the new drug, the pharmaceutical company must adopt "simulation tools" (p. 1655) aimed at highlighting the effectiveness of the new drug, as well as carrying out "educational activity" (p. 1655) which is aimed at a variety of subjects acting in the pharmaceutical supply chain. Therefore, even in the industrial marketing literature, the theme of MA extends beyond the necessary authorization dimension to include strategic aspects that need a network and interactive vision.

On the same line of thought, Guercini et al. (2020) address the issue of the pharmaceutical MA by focusing on the specificity of the interaction between the pharmaceutical company and the political actors and its impact on the sustainability of health systems. In their study, the authors highlight how MA must shift from merely negotiating conceptualization to a vision in which the content of publicprivate interaction is relevant. Besides, they emphasize how relationships with third parties in the network surrounding the dyadic relationship between the pharmaceutical company and public actor are essential for determining the effectiveness of MA in terms of the sustainability of national health systems. The authors identify five types of actors relevant to this scope: scientific societies, pharmaceutical consultants, patients and patient associations, prescribers and other influencers and other pharmaceutical companies (Guercini et al., 2020, p. 9). Thus, such studies stress the existence of a plurality of business and NBAs for MA. However, who the NBAs are, the content of the interaction between the pharmaceutical company and NBAs, and how such interaction feeds the pharmaceutical MA are all issues requiring further investigation. Therefore, the following section considers recent studies on NBAs within the IMP approach as theoretical lenses to study pharmaceutical MA.

\subsection{Network interaction with different types of actors}

Within the IMP setting, research has focused primarily on inter-firm relationships, particularly relationships with customers and suppliers, intending to understand the interactive business landscape (Håkansson et al., 2009). A key feature of the interaction pattern is the network of actors individuals, groups of individuals, business departments, companies or groups of companies - that initiate, develop and end business relationships with other actors, and their activities are based on direct and indirect control over resources, as suggested by the actor-resource-activity (ARA) model of business relationships (Håkansson and Johanson, 1992; Håkansson and Snehota, 1995). Concerning the actor dimension, IMP scholars recognize that there are still many conceptual and empirical areas that require further investigation (Munksgaard and Ford, 2017), and attention should be directed to other types of actors, such as policymakers or social actors.

There is a stream of literature that proposes a taxonomy of such actors and defines them as "NBAs," with a focus on their interdependencies, to enlarge the scope of industrial networks and depict an extended business network (Welch and Wilkinson, 2004; Hadjikhani and Thilenius, 2005). This study adopts such a definition. Even if the role and relevance of different actors in the development of business networks have been acknowledged (Håkansson and Waluszewski, 2013), the analysis of NBAs in the IMP domain still suffers from fragmentation and requires additional effort. Such effort is also needed in light of the increasing complexity of the overall business landscape characterized by rapid social, institutional and technological change (Alcácer et al., 2016). Integrating NBAs in industrial marketing studies allows depicting a complete image of the interactions among different actors and an in-depth understanding of firms' behavior (Carloni et al., 2019).

A relevant issue is the typology of NBAs. The two main categories include actors in a public sphere, namely, political and social actors (Bengtson and Hadjikhani, 2010). The importance of political actors has been stressed in the IMP domain (Håkansson and Snehota, 2017). The category of political actors includes politicians, governments and 
governmental agencies at the local, national, and supranational levels (Linné and Shih, 2013; Bengtson et al., 2009b). The role of political actors appears relevant in the context of innovation, as they support innovation processes and create technical and organizational resource interfaces that allow the firm to gain strategic political resources, such as legitimacy, power, influence and lobbying (Linné and Shih, 2013). Additionally, innovation policies set the ground for interaction between academia, industry, public and private sectors, as they are driven by the need for mutual adjustment and alignment of actors' divergent interests and resources (Hoholm and Araujo, 2017).

The second category is that of social actors. This category includes civil society, firms' stakeholders, non-profit organizations and non-governmental organizations (NGOs) (Esse et al., 2012; Leite and Latifi, 2016). Leite and Latifi (2016) maintain that interacting with social actors enables access to intangible resources valuable to address sustainability issues, promote innovation and achieve social impact. The role of social actors, especially NGOs, has grown in terms of influence, as they act as social movements and intermediaries between business actors and society and promote collective initiatives concerning environmental and health issues. In addition, the interaction with social actors allows acquiring social legitimacy, namely, the legitimate position of firms is strengthen, and their market position is positively affected (Bengtson and Hadjikhani, 2010).

There is also another category of NBAs, namely, universities and research centres. Papers by IMP scholars mention these actors among other NBAs and consider them as public organizations (Mandják and Simon, 2016). These actors are considered relevant in the field of innovation for their knowledge development, which is "the most important source of potential innovations" (Waluszewski, 2011, p. 144). Therefore, policymakers foster collaborations among universities, business actors, research centres and the public sector to develop settings of innovation (Eklinder-Frick et al., 2018).

Drawing on the study of Bengtson and Pahlberg (2009), Bengtson and Hadjikhani (2010) assume that firms are embedded in a network made of both business and NBAs, and they all create a set of socio-political and economic exchanges that interconnect different types of actors. This view is applied in the context of firms' internationalization, but it can also refer to the domestic market.

Thus, there is a triadic interaction between business, political and social actors that can be examined within the "extended business network" concept (Thilenius et al., 2016; Latifi, 2013). This view implies extending the business network to reconsider some neglected aspects, such as the existence of other vital counterparts, including NBAs among which non-economic exchanges may occur (Easton and Araujo, 1992). Some scholars see business and non-business networks as distinct but related, interacting and crossing over (Mandják and Simon, 2016; Bengtson et al., 2009a). Sometimes the interactions between business and NBAs may have an episodic nature, activated only when social or political issues arise, "sleeping" in the remaining time (Bengtson and Hadjikhani, 2010).

The extended business network resulting from the triadic interaction between business, political and social actors can be explained through some interaction elements: resource commitment, knowledge and legitimacy (Hadjikhani et al., 2008) (Figure 1). Resource commitment concerns the size of the investment or the number of actions towards the counterpart and its connected actors. Such commitment can require, for example, "the establishment of a political unit in the firms' organizations, investing in lobbying organizations, or devotion of resources towards social organizations to aid their mission" (Bengtson and Hadjikhani, 2010, p. 7). Knowledge can be the driving force for or/and an outcome of this commitment and concerns the knowledge and experience that a business actor has about socio-political actors in a certain market. Thus, commitment and knowledge in the social and political layer support the business layer. Legitimacy is, in turn, defined as the position of a certain actor recognized by the other actors in a specific business network. The development and maintaining of a legitimate position are related to the resource commitment and the knowledge developed in the interrelated ties. The higher the accumulation of legitimacies reached in both business and socio-political relationships, the higher the legitimacy position reached by a firm.

Within this framework, the relevance of NBAs has recently attracted the attention of industrial marketing scholars that have stressed the features of public-private partnerships (Hahn and Gold, 2014) and public-private interactions (PPIs) (Smyth and Edkins, 2007; Guzmán and Sierra, 2012). Research in this area underlines the need for a major collaboration between business and NBAs, especially the ones in the public sphere, for the opportunities it offers in terms of value co-creation and the innovativeness of the public system (Nissen et al., 2014; Leite and Bengtson, 2018; Elbe et al., 2018), as well as the positive effects it may generate for the society. However, some recent contributions highlight how PPI, compared to traditional business-to-business relationships, involves relationships with NBAs at different levels. This is particularly true for political actors that can be placed at a central level or decentralized levels (Guercini and Tunisini, 2017), such as local levels, and this fragmentation may cause difficulties and liabilities in the relationship (Mattsson and Andersson, 2019; Wagrell and Baraldi, 2019). Additionally, the interaction with NBAs, especially the political ones, may take place in a highly regulated context with formal norms and procedures (Oruezabala and Rico, 2012), in which the interaction between a company and political actors is hindered by "complex and formalized procedures forbidding direct interactions" and is "strictly price-based" (Wagrell and Baraldi, 2019, p. 278). Thus, much of the attention is devoted to political actors, while a comprehensive view of business and NBAs as part of an extended business network in a highly regulated market is missing, and the study of MA, which involves a multiplicity of actors and develops in a regulated context, can contribute to filling this gap.

\section{Methodology}

This study adopts an industrial marketing approach to investigate pharmaceutical MA and the interaction between the pharmaceutical company and a set of business and NBAs. 
Figure 1 Types of interacting actors and interaction elements

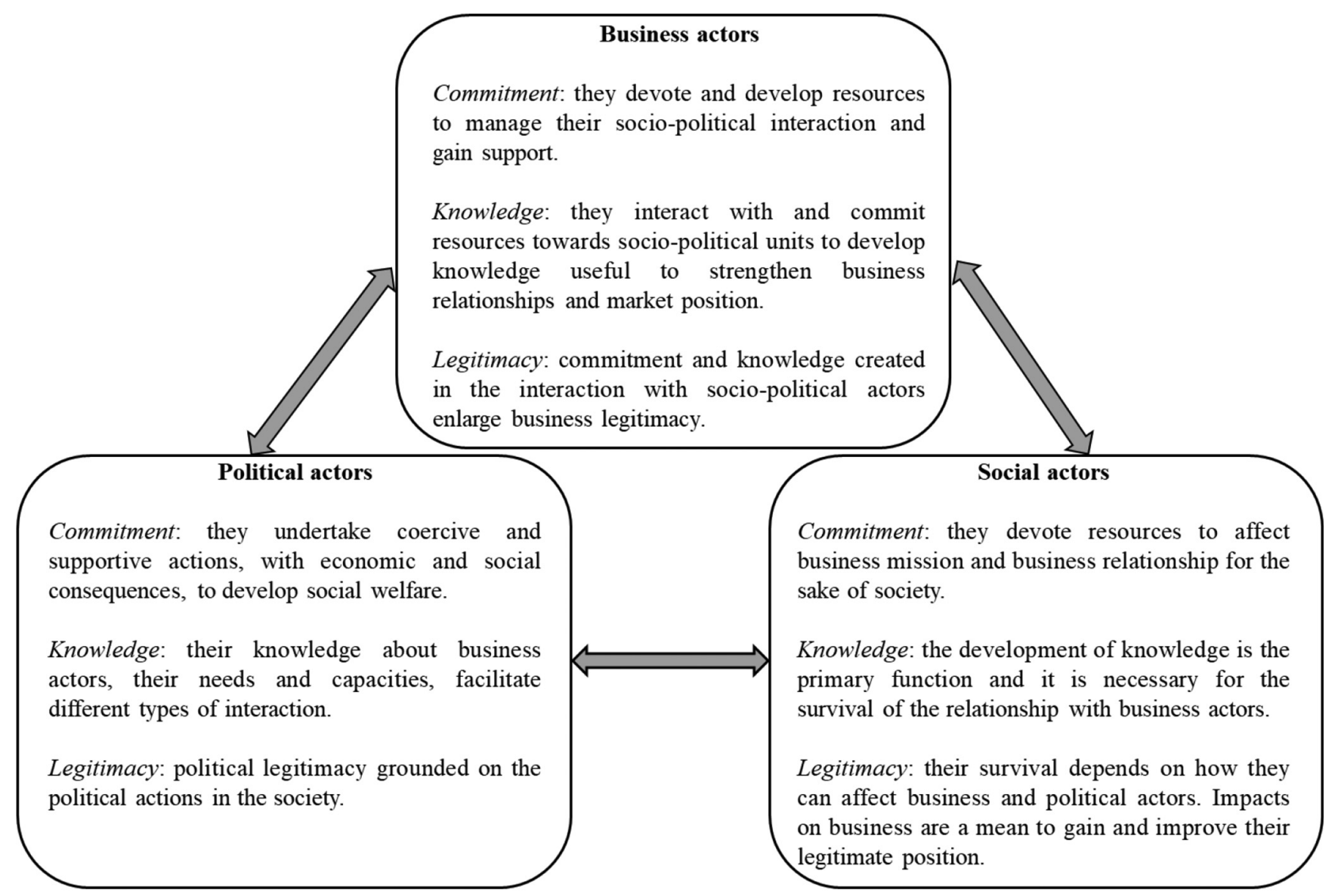

Source: Our adaptation from Bengtson and Hadjikhani (2010)

Research on this topic is scarce, as MA is a topical and fastevolving phenomenon. For these reasons, an explorative approach (Eisenhardt and Graebner, 2007) is adopted in the paper. In particular, a qualitative interpretivist approach was selected as the most appropriate method for the aim of this study, with interviews as the primary method of data collection. A peculiarity of this methodology is that it allows emphasizing the contextual conditions in which events take place (Guba and Lincoln, 1994) and understanding actors' feelings, experiences, ideas and perceptions of the subject under investigation (Denzin and Lincoln, 2008). The research was carried out in several steps.

First, a preliminary observation was included as part of the research design. As suggested by Creswell and Miller (2000), preliminary observation aims at increasing the validity of the study, create trust among the participants and "find gatekeepers to allow access to people and sites, establish rapport so that participants are comfortable disclosing information, and reciprocate by giving back to people being studied" (Creswell and Miller, 2000, p. 128). The preliminary observation started in 2018 and continued in 2019 and consisted of participation of the research team in events on pharmaceutical strategic marketing and MA, factory tours and thematic workshops concerning the negotiation and MA of an innovative drug for the treatment of rare diseases. Thus, the preliminary observation resulted in social activities that favoured the interaction with entrepreneurs, managers, consultants, patients and other experts in the pharmaceutical and health-care fields, including public actors from local, regional and national institutions. Interactions were carried out in a less formal way that helped the establishment of communication channels and the researcher-manager interface (Guercini, 2004). The most relevant conversations and speeches were recorded as field notes.

The preliminary observation enabled the research team to understand the relevance of the topic, gain preliminary background on MA and provide a basis for developing the scope and orientation of the research. The observation revealed the highly strategic and complex nature of MA and the related network of interaction with business and NBAs, which, in the perspective of a pharmaceutical company, require many years of experience in the field and the management by expert managers in the company. The preliminary observations were also functional to the identification of potential key informants (second step of the research process) and the validation of a set of selection criteria, which were defined as the following: lasting experience (at least ten years) in pharmaceutical or related companies, including consulting companies, ministries and 
other public institutions; top positions in such companies; and direct or indirect experience with MA-related functions and activities. Based on these criteria, potential informants were identified for the interviews: 16 key informants were selected based on this purposive sampling. Among them, nine are top managers in multinational pharmaceutical companies based in Italy. Three are pharmaceutical consultants with previous experience as top managers at pharmaceutical companies. Two respondents have top positions in public organizations, one as a hospital pharmacy director, the other as a member of AGENAS, the national agency for regional health services. One respondent is a member of a patients' association, and another responder is a former deputy and council member. The availability of key informants was fundamental to the selection process owing to the sensitivity of the topic under investigation.

Thus, the third step of the research process included data collection through interviews with key informants. A total of 36 in-depth, semi-structured interviews, which can be considered as the preferred data collection method for exploratory research, were conducted with the selected informants. Respondents' membership to different public and private organizations guaranteed multiple perspectives on MA enabled a deeper understanding of the phenomenon under study, and limited self-reported biases that may compromise the reliability of the research. The authors also believed that the number of respondents was appropriate because, interview after interview, the discussion reached saturation and broad consensus around MA issues, no new themes emerged and additional interviews would not have added further information (Guest et al., 2006).

A semi-structured interview guideline was developed, including six sections and sub-sections as follows:

1 respondents' profile: role currently held, previous experience;

2 pharmaceutical MA: definition, features and evolution over time;

3 relevant actors for MA: list of the main categories of business actors, list of the main categories of NBAs;

4 interaction with each actor: evolution over time of relationships with the various categories of actors, content and features of the interaction, examples regarding experiences of MA of various ethical drugs;

5 barriers of MA: difficulties encountered in managing the MA process, difficulties encountered in the interaction with the various actors; and

6 country-specific factors: specificities of the MA in Italy that influence the management of the process and the interaction with the various actors; benchmark with other countries.

The answers provided all concerned the Italian context, with comparisons with other countries. For each section, respondents were asked about their ideas, experience and perceptions about the issues around MA and gradually guided into a detailed discussion. Even if the respondents come from different backgrounds, the aforementioned data collection tool was used for all the interviews, as the focus was on individual experiences and perceptions, which emerged without difficulty thanks to the breadth and transversality of the questions posed, formulated on purpose to stimulate a discussion that would then inevitably revolve around the respondent's background and experiences. Interviews were conducted face-to-face, via Skype and GMeet in 2019 and 2020. They were conducted in Italian and then translated into English. Each interview lasted between 35 and $120 \mathrm{~min}$. The research team took extensive notes, and each interview was recorded and transcribed (about 520 pages of verbatim transcript). Given the confidential nature of the interview data, respondents were given fictitious names (Table 1).

As a fourth step of the research process, data analysis consisted of a subjective interpretation of transcripts in the form of written synthesis and systematizations of recurrent topics. This analysis was carried out separately by each member of the research team, followed by a comparison of results. Such a comparison between the subjective interpretations consisted of a discussion of the individual views to verify that the interpretations respected the actual words of the interviewees, without distortion and the degree of convergence on the main topics emerging from the interviews. This interpretative endeavour led to the creation of shared categories (recurring topics) and the related relevant quotes concerning a perspective of MA as relational-driven activity in a highly regulated market, the multiplicity of business and NBAs involved and the content of each interaction. Such recurring topics are developed in Section 4 . The steps of the research process are represented in Figure 2.

\section{Findings}

\subsection{Market access in a highly regulated market}

The first issue that emerged from the interviews concerns a perspective on MA that goes beyond negotiation and is relational-driven: "the relational dimension is the main one, as the pharmaceutical company interacts with a multiplicity of political and non-institutional actors" (R5). It is, however, wrong to think that these relationships are concentrated only in the proper phase of negotiation with the political actors at the central level. In fact, "the complex number of interactions with multiple actors that support the MA starts well before the negotiation phase, since the phases of clinical research. In particular, we involve several actors from the health system, especially pharmacologists, clinicians, economists, and specialists doctors. The aim is to gain knowledge about the socalled proof of concept, which refers to the early clinical drug development, and the definition of the target population for the new drug" (R15). There is consensus on the fact that MA should be considered as "pervasive within the pharmaceutical company, starting from the phases of $\mathrm{R} \& \mathrm{D}$ and clinical research" (R11).

At the central level, the main interlocutor is "Agenzia Italiana del Farmaco" (AIFA, the Italian medicine agency), which provides market authorization: "MA mainly concerns the moment of negotiation with the AIFA commission, in which it is decided to authorize access, and the price and reimbursement mechanisms" (R6). Negotiation implies the use of supporting tools to justify the approval of a new drug and its proposed price. This aspect is highlighted by one of the respondents who underlines how "all the tools are aimed at highlighting the appropriateness of the new drug in providing an effective solution of a clinical problem, but also its economic 
Table 1 Preliminary observation, informants and interviews

\begin{tabular}{|c|c|c|c|}
\hline \multicolumn{4}{|c|}{ Preliminary observation } \\
\hline \multicolumn{3}{|l|}{ Activities } & Year \\
\hline \multicolumn{3}{|c|}{ Two factory visits at multinational pharmaceutical companies } & 2019 \\
\hline \multicolumn{3}{|c|}{ Two events on pharmaceutical strategic marketing and MA } & 2018,2019 \\
\hline \multicolumn{3}{|c|}{ Three thematic workshops on MA } & 2019 \\
\hline \multicolumn{3}{|c|}{ Informal conversations with experts in the field } & 2018,2019 \\
\hline Respondents & Data collection through in-depth interviews & No. of interviews & Year \\
\hline $\mathrm{R} 1$ & Health, Economics and Outcomes Research Specialist & 2 & 2019 \\
\hline R2 & Marketing \& Communication Consultant for pharmaceutical companies & 3 & 2019,2020 \\
\hline R3 & Pharmaceutical Consultant & 3 & 2019 \\
\hline R4 & Regional Commercial Director & 4 & 2019,2020 \\
\hline R5 & Corporate Affairs Director & 5 & 2019,2020 \\
\hline R6 & Regulatory \& Price Reimbursement Access Director & 4 & 2019,2020 \\
\hline R7 & Member of a Patient Association & 1 & 2019 \\
\hline R8 & Strategic \& Trade Marketing Consultant & 3 & 2019 \\
\hline R9 & Regulatory Affairs Sr Manager & 1 & 2020 \\
\hline R10 & Former Deputy and Council Member & 1 & 2020 \\
\hline R11 & Market Access, Government Affairs \& Business Intelligence Sr Director & 3 & 2019 \\
\hline R12 & Hospital Pharmacy Director & 1 & 2020 \\
\hline R13 & Market Access Manager & 2 & 2019,2020 \\
\hline R14 & Institutional Affairs Head & 1 & 2019 \\
\hline R15 & External Relations, Market Access and Regulatory Director & 1 & 2019 \\
\hline$\underline{R} 16$ & Health Economic and Market Access Consultant, Member of AGENAS & 1 & 2019 \\
\hline
\end{tabular}

and social sustainability" (R7). As stated by another respondent: "we present to the AIFA commission a dossier that includes information on costs, therapeutic effectiveness, impacts for public spending. We also propose a price request [...] then the negotiation starts" (R4). For an effective negotiation, "The analysis should be comparative with existing drugs. Even better if you compare the new drug with the best in class, demonstrating the differentiating factors and, more generally, the value proposition that the new drug wants to make" (R12). Even if the negotiations are strongly based on the price and reimbursement mechanism, it is also acknowledged "the focus should not be on the lowest price but the incidence of the pathology" (R3). A long-term perspective should be preferred: "the budget impact on health spending is crucial, but the crucial point that should be considered is how today's expenditure allows savings in future years" (R6).

When negotiating with AIFA, the pharmaceutical company stresses the interaction with other business and NBAs, actors come into play, as pointed out by one informant: "many elements enter into negotiation. First, one can present to the MA commission internal scientific works and economics studies, developed with clinicians, pharmacologists, specialist doctors, and economists during the phases of clinical research. Of course, that is a material internal to the company, but a good approach is to include also studies from third parties, such as universities, to legitimate the dossier presented" (R3). After the negotiation with AIFA at the central level, which is an activity that also involves the ethic committees, the negotiation moves to the regional and local levels: "the phase of the insertion into the regional drug register is preceded and followed by a series of interactions with actors who have a decision-making or influence role, through continuous communication activities aimed at demonstrating the value proposition and what differentiates the new drug compared to the existing therapies" (R11). Despite these efforts, it can be difficult to create a dialogue with the political actor, especially at the national level, as noted by a respondent who claims "the problem is the lack of dialogue with political actors (governments, public administrations, members of the commission). In some cases, you can't talk to anyone, and you can only explain the value of your new drug through documentation and the dossier. You just send them and then wait for the approval or the rejection" (R10). A transparent and in-depth interaction with the political actors, before the negotiation phase, would make it possible to "gather knowledge about what the overall health needs and priorities are" (R11), while, during negotiation, it "would allow to better clarify what the unmet needs and the target population that the new drug intends to satisfy are, and the differential therapeutic benefits compared to what is already on the market" (R9).

\subsection{Actors involved and content of the interaction}

The discovery of a new drug may involve other pharmaceutical companies in partnerships aimed at developing new molecules. In this case, MA activities require the combined effort of the pharmaceutical companies that are part of the agreement. However, the plurality of actors involved does not end here. In fact, in the subsequent steps, which are those immediately preceding the negotiation and launch of the drug on the market, the pharmaceutical company relates to other relevant actors belonging to both a business and a socio-political. In particular, "hospital directors, universities, and ethics committees are involved in randomized clinical trials and the definition of the dossier of the drug to be negotiated. Also, in 
Figure 2 Research process

\begin{tabular}{|c|}
\hline $\begin{array}{l}\text { 1. Preliminary observation: } \\
\text { - participation to events (2), factory visits (2), thematic } \\
\text { workshops ( } 3 \text { ) } \\
\text { - informal conversations with experts in the field } \\
\text { - period: from February } 2018 \text { to January } 2019\end{array}$ \\
\hline $\begin{array}{l}\text { 2. Informants selection criteria: } \\
\text { - lasting experience (at least } 10 \text { years) in pharmaceutical or } \\
\text { related companies, including consulting companies, ministries, } \\
\text { and other public institutions } \\
\text { - top positions in such companies } \\
\text { - direct or indirect experience with MA-related functions and } \\
\text { activities. } \\
\longrightarrow \text { Selection of } 16 \text { key informants }\end{array}$ \\
\hline $\begin{array}{l}\text { 3. Data collection: } \\
\text { - data collection tool: semi-structured interview guideline with } \\
\text { six sections and subsections } \\
\text { - } 36 \text { interviews } \\
\text { - } \text { duration: from } 35 \text { to } 120 \text { minutes } \\
\text { - } \text { period: from February } 2019 \text { to June } 2020 \\
\text { - } 520 \text { pages of verbatim transcript }\end{array}$ \\
\hline $\begin{array}{l}\text { 4. Data analysis: } \\
\text { - subjective interpretation by each author } \\
\text { - discussion of the individual views } \\
\text { - convergence on recurring topics } \\
\text { - development of each topic }\end{array}$ \\
\hline
\end{tabular}

these moments of the MA, other key opinion leaders intervene, coming in particular from citizenship and patients" (R16). One of the key social actors is the patient, at the centre of the activities of pharmaceutical companies as a final interlocutor: "There is an empowerment of patients. They are organized in associations; some have a relevant role as influencers at the regional and national levels, affecting doctors' and politicians' decisions. Members of patient associations are part of the commissions that decide the access of a drug, recently a representative of patient associations has become a member of AIFA" (R6). Pharmaceutical companies organize meetings with patient associations to establish a dialogue, educate them, gain information about their needs and obtain legitimacy. This is not always possible, as, in some Italian regions, only public actors (local government) are allowed to organize periodic meetings with patient associations, not pharmaceutical companies. As claimed by a member of a patient association, "it is fundamental for us to interact with politicians but also with pharmaceutical companies. We are bearers of a knowledge that only those with a disease can have, and we try to exploit it to express our unmet needs and, if possible, speed up the access to the market of some drugs that are fundamental for us" (R7).

Citizenship in general also seems to have an active role for pharmaceutical companies that increasingly interact with the community to educate them on the correct use of medicines and, at the same time, listen to their needs. The pharmacist intervenes as an intermediary, taking on a leading role for MA, especially regarding hospital pharmacists who have decisionmaking power about purchasing and using a new drug. Scientific societies have a role, too, as they "intervene in market access at certain times and interact with pharmaceutical companies in the phase of defining the positioning of the drug and guidelines" (R8).

At the regional level, the pharmaceutical companies, through regional affair managers, interact with political actors, such as the Presidents of the regions, the departments (health and education, in particular) and the budget manager: "With these public actors, we discuss industrial issues and possible partnerships. These do not concern MA but could partially influence it, since the pharmaceutical company can be configured as a key actor operating on a certain territory and, therefore, it can obtain legitimacy in the social and political sphere through joint activities developed in the interaction with the political actor" (R10). There are also subgroups of political actors at the regional level, such as the director of regional drug policies, the regional administrative director and the regional health director. At the local level, these figures must be multiplied by each ASL (local health-care institution), further multiplying the actors and the levels of interaction. The importance of these actors is because the market authorization provided by AIFA does not guarantee the inclusion of the new drug in regional or local drug registers. In some cases, there are then the directors of health districts, further multiplying actors and access levels: "The identification of these actors and the maintenance of medium/long-term relationships depends very much on the experience of the pharmaceutical managers, given complexity and fragmentation of the system. Sometimes identifying the right interlocutors is also a matter of luck" (R4).

Thus, the multiplicity of business and NBAs corresponds to multiple levels of interaction. This is typical of countries like Italy, in which the fragmentation is greater owing to the high levels of independence that regions have in terms of the organization of regional services. One of the respondents notes, "aside from a national health care system, there are many different regional health systems, each with their decisionmaking levels and assessment criteria. This mechanism generates significant differences in geographical access" (R10). The variety of business and NBAs, the fragmentation and the different levels of interaction make the activities connected to MA very complex to manage, and "the prerogative of expert managers and dedicated organizational units" (R2). However, all the respondents agree on the strategic nature of MA that cannot be limited to mere negotiation but concerns the interaction with business-social-political actors since the early stages of clinical research on the new drug. For this reason, it is believed that "MA must be a widespread orientation within the pharmaceutical company, it is a connecting function between the other company's functions and the surrounding environment" (R13). The multiplicity of business and NBAs involved implies that "the wording of MA itself is limiting. To date, it is more appropriate to think about Patient Access, as it is still the patient and his needs to drive the whole process. Or, more in general, a value proposition perspective should be adopted, in which the value of the new drug is given not only by its therapeutic efficacy but also by the plurality of actors contribute to its definition" (R15). 


\section{Discussion and theoretical implications}

The findings of this study reveal that MA can be seen as a relational-driven activity with specific features owing to the highly regulated nature of the pharmaceutical industry; there is a multiplicity of business and NBAs involved in the MA activities with whom pharmaceutical companies interact to acquire knowledge, legitimacy and make MA timely and effective; and the interaction with each category of actors has specific content. More specifically, the findings of the empirical investigation suggest that pharmaceutical companies adopt an extended view of the business network for MA, through the identification of a series of business and NBAs, with whom to interact to carry out the MA activities.

Concerning $R Q 1$, it is possible to affirm that the MA activities include a relevant set of relationships that the pharmaceutical company establishes with business and NBAs, as part of an extended business network. A salient aspect of the application of an extended business network allows managing a potential tradeoff linked to the highly regulated nature of the market. In fact, on the one hand, the interaction between the pharmaceutical company and other actors (policymakers and social actors) is strongly conditioned by regulations and rules and, in some cases, limited or denied. On the other hand, interaction with NBAs needs to be developed for the effectiveness and timeliness of MA. In other words, the interviews show a strong interdependence among the various actors involved in the MA of new drugs, as interacting for MA contributes in various ways to generate knowledge, legitimize the pharmaceutical company, and, more in general, to generate greater integration between the objectives of the different parties interested in a new drug. Overcoming the potential trade-off in highly regulated markets, between limitations to interaction and the need to develop relationships with NBAs, implies a rethinking of the MA. Therefore, MA encompasses bureaucratic procedures and formalized requirements, as well as relational skills that allow the pharmaceutical company to interact in compliance with rules and regulations.

Additionally, the empirical investigation emphasizes the relevance of a processual view of MA, which is not limited to formalized procedures centred on the moment of negotiation with the political actors. This is in line with previous studies on the pharmaceutical MA that emphasize its strategic nature, with a dedicated organizational unit in the pharmaceutical company (Schiavone and Simoni, 2019) that testifies a strong resource commitment (Hadjikhani et al., 2008). It is clear from the interviewees' words that the moment of negotiation with the political actors is central to the definition of the pricereimbursement mechanism for the new drug, and it represents the moment of synthesis of a series of activities implemented for this purpose by MA managers over time (Guercini et al., 2020). The MA concept that acquires centrality from the interviewees' words requires an interpretative shift from a price-driven, in which negotiation is the focus of attention to a relational-driven perspective that focuses on the legitimacy and the improved possibility for access to which various business and NBAs contribute. The approach to a relational-driven MA implies the extension of the MA activities and the role of different business and NBAs for enhancing legitimacy in the moment of negotiation with authorities.
Concerning $R Q 2$, the findings show a series of business and NBAs that contribute to enlarge the scope of the industrial network and depict a complete image of the interactions (Hadjikhani and Thilenius, 2005; Carloni et al., 2019), involved at different phases of the MA. The set of actors includes business ones operating in the pharmaceutical sector, universities and scientific societies, socio-political actors. Patients are the main social actors, and citizens' associations are part of this category. The role of social actors, especially patient associations, has grown in terms of influence, as they act as social movements and intermediaries between business actors, political actors and the whole society and promote initiatives concerning health issues. The interaction with social actors allows acquiring social legitimacy, namely, the legitimate position of firms is strengthen, and their market position is positively affected (Bengtson and Hadjikhani, 2010). The political actors are those involved at national, regional and local levels, including governments, regulatory authorities, ethics committees and other political actors from the public sphere, consistently with the previous categorizations provided in the industrial marketing literature (Bengtson et al., 2009b; Linné and Shih, 2013). However, the interaction with political actors takes place in a highly regulated context with formal norms and procedures, as stated in previous studies (Oruezabala and Rico, 2012).

This multiplicity of actors is embedded in the extended business network (Thilenius et al., 2016; Latifi, 2013) and is relevant for various reasons. First, they are bearers of knowledge that contributes to the definition of the value of a new drug. Each NBA provides, in the interaction, content that the pharmaceutical company can leverage to define the value that the new drug can generate. Second, the pharmaceutical company carries out an educational activity, as highlighted in the literature, concerning the new drug or, more in general, a disease. This happens particularly in the interaction with social actors and local and regional political actors. Therefore, every single dyadic relationship activates bidirectional flows: the pharmaceutical company, on the one hand, commits resources and acquires knowledge that contributes to the definition of the value and, on the other hand, educates about the new drug and how it fits with the concept of the value expressed by NBAs. Thus, such interaction consists of a set of socio-political and economic exchanges that interconnect different types of actors (Hadjikhani et al., 2008).

Furthermore, the relationships with different business and NBAs, especially the social ones, contribute to implementing more effective MA activities at the moment of negotiation with political actors because such activities are based on the concept of value that has been previously legitimized through the interaction with business and NBAs. Thus, the findings confirm the need for a major collaboration between business and NBAs, especially the socio-political ones, for the opportunities it offers in terms of value co-creation, innovativeness, legitimization and positive effects both for pharmaceutical companies, society and the health system (Nissen et al., 2014; Leite and Bengtson, 2018), Figure 3 shows the contribution of business and NBAs to relational-driven MA.

From a theoretical point of view, this paper contributes as follows:

- Compared to the previous literature on MA (Panteli et al., 2015; Kumar et al., 2014), it emphasizes the importance of an industrial marketing perspective. MA cannot be interpreted as an activity that the pharmaceutical company can set up 
Figure 3 Interaction between business and NBAs for relational-driven MA

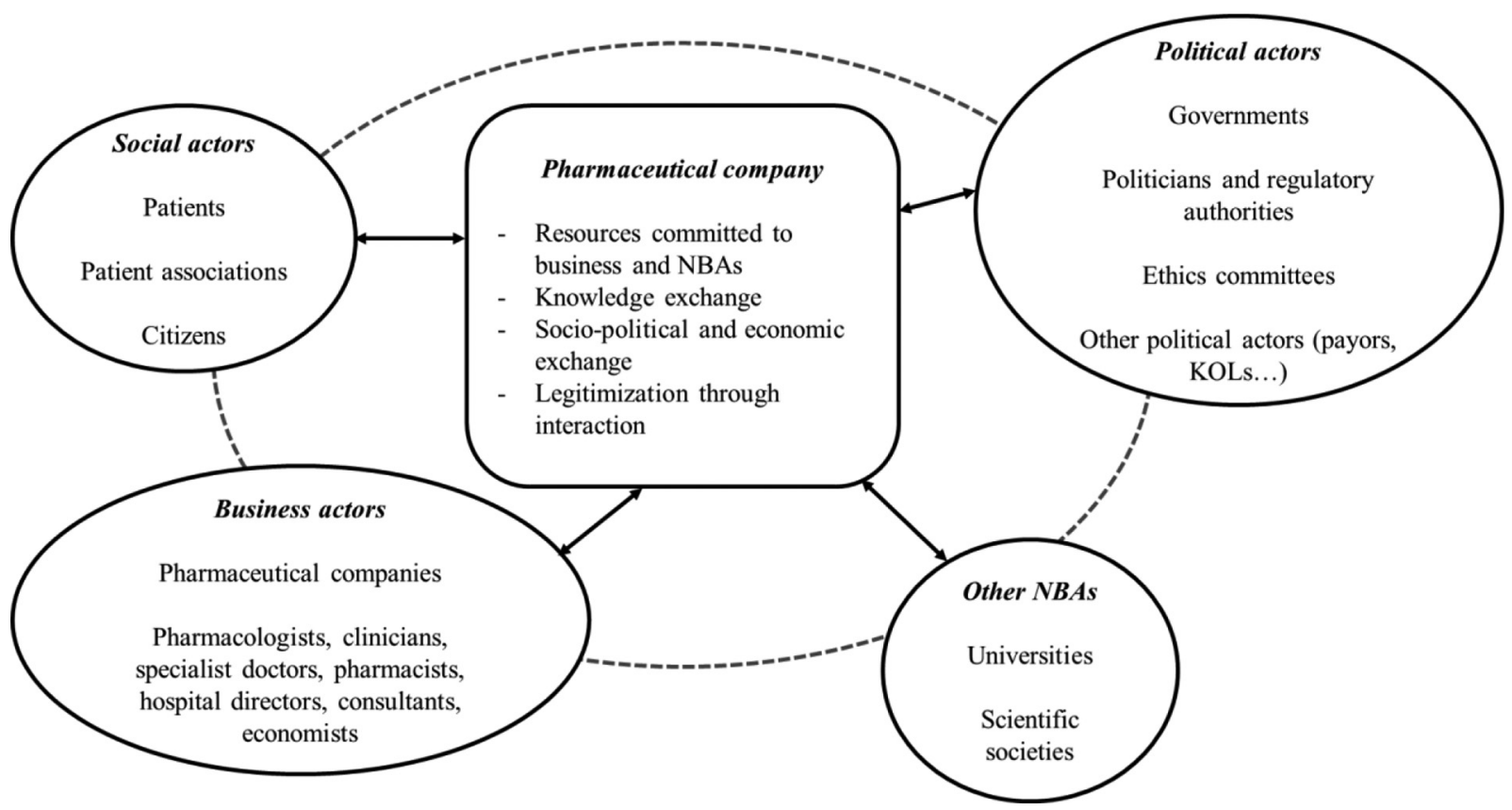

independently, but it must be conceived as an activity whose content arises from the interaction with other business and NBAs, and the interdependence among these actors for a win-win MA can help to overcome a conceptualization of MA as a mere negotiation-related topic.

- It advances recent industrial marketing literature (Håkansson and Waluszewski, 2013; Bengtson and Hadjikhani, 2010) on NBAs by addressing their role in terms of knowledge and legitimacy. It can be argued that NBAs refer to a heterogeneous category of actors that should be considered as a structural part of the extended company's network and require a clear understanding of who these actors are and to what extent the company can involve them.

- It shows that rules and norms may affect the notion of the extended business network itself and, hence, the role that NBAs may play and how the company may relate to them. Consequently, translating relational approaches typical of business contexts to NBAs cannot ignore the highly regulated nature of the market in which the company operates.

\section{Practical implications, limits and future research directions}

This paper also advances implications for society and managers. Taking a conceptualization of MA as a relational-driven process leads to a faster process of launching the new drug, as the definition of the value is shared and legitimated from the beginning with a plurality of actors and, therefore, more clearly demonstrable to decision-makers. The recent COVID-19 pandemic is an emblematic, although dramatic, proof that shows how the MA of new vaccines is connected to the interdependence among different actors. This study suggests to policymakers, institutions and pharmaceutical companies the opportunity to rethink how NBAs could be part of the MA activities. The need to integrate different aims is structural to MA, and new forms of NBAs involvement in MA may favour long-term positive effects in the discovery and diffusion of new drugs.

From a managerial perspective, this study suggests to pharmaceutical companies the need to include NBAs in their network to improve the timeliness and effectiveness of negotiation for marketing authorization. Besides, MA managers should invest in developing the content of the interaction with business and NBAs. Relational skills and the ability to monitor the environment to identify the categories of relevant actors should be enhanced within the organizational unit dedicated to the MA. More generally, for all companies operating in highly regulated markets, it is necessary to keep in mind that interaction is possible and manageable with sociopolitical actors and to have cross-functional roles that create a dialogue within the organization and with the surrounding set of business and NBAs. In these contexts, a balance must be found between procedural and regulatory aspects and a more relational dimension aimed at cultivating the content of the interaction. The technical/procedural/regulatory components must be developed hand in hand with the relational ones.

There are some limitations to this study that may represent an agenda for future research. First, this study considers only the Italian context as an empirical setting. Although the Italian context is relevant for its peculiarities and complexities, future research may benefit from a cross-national comparison aimed at identifying commonalities and differences in the approach to MA. In particular, the analysis of MA in different national contexts may contribute to better understand the role of NBAs for MA.

Second, this study considers the MA of ethical drugs without distinguishing them according to the degree of innovation. Another interesting avenue for future research should include the investigation of MA compared to the degree of innovation of the 
new drug, as MA activities may be different depending on the innovative content of a new drug and so the role of NBAs.

Finally, this paper is based on data collected through interviews to bring out the experience and point of view of interlocutors involved in MA activities. The qualitative interpretivist approach adopted in the present study could lead to biases that can be overcome by analyzing single or multiple case studies of pharmaceutical companies, aiming at considering the specific sets of relationships activated with business and NBAs. Moreover, although this paper considers some public actors, besides the industrial ones, in the empirical investigation, further research could also be aimed at enlarging their perspective through an ad-hoc study.

Despite these limits, this paper sheds light on the interdependence among actors for MA, pointing out the importance of conceiving NBAs as relevant actors of the extended network and suggesting how the value created through interaction may be a beacon to follow for operating in highly regulated markets.

\section{Conclusions}

To conclude, this study dealt with MA, which is a relevant industrial marketing issue for pharmaceutical companies as well as for national health systems. This paper pointed out how pharmaceutical companies should operate in a highly regulated context in which it is essential to understand how to interact with business and NBAs. While in other business contexts, the activation and maintaining of relationships, even with NBAs, can reflect the normal functioning of a business-to-business market, in the case of the pharmaceutical sector, instead, there can be different ways to activate and manage the relationship, depending on the category of NBAs. As stated in the foregoing, in some cases, the interaction may be hindered or denied. This means that the relational approach that the pharmaceutical company can set up requires adaptations and specificities. This paper represents an attempt to show how pharmaceutical companies can relate to other actors, speed up the process and contribute to a long-term vision of the effects of MA.

\section{Note}

1 These are institutions such as the Food and Drug Administration (FDA) in the USA, the European Medicines Agency (EMA), the "Agenzia Italiana del Farmaco" (AIFA) in Italy, to cite a few.

\section{References}

Alcácer, J., Cantwell, J. and Piscitiello, L. (2016), "Internationalization in the information age: a new era for places, firms, and international business networks?", fournal of International Business Studies, Vol. 47 No. 5, pp. 499-512.

Allarakhia, M. and Walsh, S. (2011), "Managing knowledge assets under conditions of radical change: the case of the pharmaceutical industry", Technovation, Vol. 31 Nos 2/3, pp. 105-117.

Bengtson, A. and Hadjikhani, A. (2010), "NBAs in business networks”, 26th IMP Conference, Budapest.
Bengtson, A. and Pahlberg, C. (2009), "Political embeddedness of technological development-the IgY case", International Fournal of Business Environment, Vol. 2 No. 4, pp. 418-434.

Bengtson, A., Hadjikhani, A. and Pahlberg, C. (2009a), "Adding a political dimension to business research", International fournal of Business Environment, Vol. 2 No. 4, pp. 391-399.

Bengtson, A., Pahlberg, C. and Pourmand, F. (2009b), "Small firms' interaction with political organization in the European Union”, Industrial Marketing Management, Vol. 38 No. 6, pp. 687-697.

Bianchi, M., Cavaliere, A., Chiaroni, D., Frattini, F. and Chiesa, V. (2011), "Organisational modes for open innovation in the bio-pharmaceutical industry: an exploratory analysis", Technovation, Vol. 31 No. 1, pp. 22-33.

Carloni, E., Bocconcelli, R. and Pagano, A. (2019), "The role of NBAs in business networks", Annual Conference of the SIM - Società Italiana Marketing.

Creswell, J.W. and Miller, D.L. (2000), "Determining validity in qualitative inquiry", Theory into Practice, Vol. 39 No. 3, pp. 124-130.

Data, G. and Mariani, P. (2015), Market Access Nel Settore Healthcare. Strategie, Attori, Attività e Processi: Strategie, Attori, Attività e Processi, Vol. 102, Milano, FrancoAngeli.

Denzin, N.K. and Lincoln, Y.S. (2008), Collecting and Interpreting Qualitative Materials, Vol. 3, Sage.

Easton, G. and Araujo, L. (1992), "Non-economic exchange in industrial networks", Industrial Networks: a New View of Reality, pp. 62-84.

Eisenhardt, K.M. and Graebner, M.E. (2007), "Theory building from cases: opportunities and challenges", Academy of Management Fournal, Vol. 50 No. 1, pp. 25-32.

Ekelund, M. and Persson, B. (2003), "Pharmaceutical pricing in a regulated market", Review of Economics and Statistics, Vol. 85 No. 2, pp. 298-306.

Eklinder-Frick, J.O., Perna, A. and Waluszewski, A. (2018), "Innovation in a globalized world: proximity-focused policy and border-crossing innovation projects", IMP fournal, Vol. 12 No. 2, pp. 237-257.

Elbe, J., Gebert Persson, S., Sjöstrand, F. and Ågren, K. (2018), "Network approach to public-private organizing of destinations", IMP fournal, Vol. 12 No. 2, pp. 313-332.

Esse, B., Szántó, R. and Wimmer, Á. (2012), "Business relationships and relationships with stakeholders: perception of Hungarian executives", IMP fournal, Vol. 6 No. 2, pp. 98-108.

Gambardella, A. (1992), "Competitive advantages from inhouse scientific research: the US pharmaceutical industry in the 1980s", Research Policy, Vol. 21 No. 5, pp. 391-407.

Guba, E.G. and Lincoln, Y.S. (1994), "Competing paradigms in qualitative research", in Denzin, N.K. and Lincoln, Y.S. (Eds), Handbook of Qualitative Research, Sage, Thousand Oaks, CA, pp. 105-117.

Guercini, S. and Tunisini, A. (2017), "Regional development policies", in Håkansson, H. and Snehota, I. (Eds), No Business is an Island, Emerald Publishing Limited, pp. 141-155.

Guercini, S. (2004), "Developing the researcher-manager interface in the case analysis process", Management Decision, Vol. 42 Nos 3/4, pp. 464-472.

Guercini, S., Milanesi, M. and Runfola, A. (2020), "Bridges to sustainable health systems: public-private interaction for 
market access", fournal of Business E Industrial Marketing, Vol. 35 No. 12, pp. 1929-1939.

Guest, G., Bunce, A. and Johnson, L. (2006), "How many interviews are enough? An experiment with data saturation and variability", Field Methods, Vol. 18 No. 1, pp. 59-82.

Guzmán, F. and Sierra, V. (2012), "Public-private collaborations: branded public services?”, European fournal of Marketing, Vol. 46 Nos 7/8, pp. 994-1012.

Hadjikhani, A. and Thilenius, P. (2005), NBAs in a Business Network: A Comparative Case on Firms' Actions in Developing and Developed Countries, Elsevier.

Hadjikhani, A., Lee, J.W. and Ghauri, P.N. (2008), "Network view of MNCs' socio-political behavior", Fournal of Business Research, Vol. 61 No. 9, pp. 912-924.

Hahn, R. and Gold, S. (2014), "Resources and governance in 'base of the pyramid'-partnerships: assessing collaborations between businesses and NBAs", fournal of Business Research, Vol. 67 No. 7, pp. 1321-1333.

Håkansson, H. and Snehota, I. (Eds), (2017), No Business is an Island: Making Sense of the Interactive Business World, Emerald Publishing Limited.

Håkansson, H. and Johanson, J. (1992), “A model of industrial networks", in Axelsson, B. and Easton, G. (Eds), Industrial Networks. A New View of Reality, Routledge, London, pp. 28-33.

Håkansson, H. and Snehota, I. (1995), Developing Relationships in Business Networks, Routledge, London.

Håkansson, H. and Waluszewski, A. (2013), "A never ending story - interaction patterns and economic development", Industrial Marketing Management, Vol. 42 No. 3, pp. 443-454.

Håkansson, H., Ford, D., Gadde, L.E., Snehota, I. and Waluszewski, A. (2009), Business in Networks, John Wiley \& Sons, London.

Hoholm, T. and Araujo, L. (2017), "Innovation policy in an interacted world - the role of the context”, in Håkansson, H. and Snehota, I. (Eds), No Business is an Island: Making Sense of the Interactive Business World, Emerald Publishing Limited.

Koçkaya, G. and Wertheimer, A. (2016), Pharmaceutical Market Access in Emerging Markets, SEEd, Torino.

Kumar, A., Juluru, K., Thimmaraju, P.K., Reddy, J. and Patil, A. (2014), "Pharmaceutical market access in emerging markets: concepts, components, and future", fournal of Market Access $\mathcal{E}$ Health Policy, Vol. 2 No. 1, p. 25302.

Latifi, M. (2013), "NBAs in the context of business networks: problems and opportunities", International Symposium on Extending the Business Network Approach, Uppsala, Sweden.

Leite, E. and Bengtson, A. (2018), "A business network view on value creation and capture in public-private cooperation", Industrial Marketing Management, Vol. 73, pp. 181-192.

Leite, E. and Latifi, M. (2016), "The role of NGOs in business networks: partnership in innovation", Extending the Business Network Approach, Palgrave Macmillan, London, pp. 83-97.

Linné, Å. and Shih, T. (2013), "The political embeddedness of business networks in a Chinese context: the case of a biopharmaceutical business network", IMP Fournal, Vol. 7 No. 3, pp. 180-187.

Mandják, T., Simon, J. (2016), “An old picture ... or is it? The relations between business and political networks in Hungary", IMP fournal, Vol. 10 No. 3, pp. 483-511.
Mattsson, L.G. and Andersson, P. (2019), "Private-public interaction in public service innovation processes-business model challenges for a start-up EdTech firm", fournal of Business \& Industrial Marketing, Vol. 34 No. 5, pp. 1106-1118.

Maynou, L. and Cairns, J. (2019), "What is driving HTA decision-making? Evidence from cancer drug reimbursement decisions from 6 European countries", Health Policy, Vol. 123 No. 2, pp. 130-139.

Milanesi, M., Runfola, A. and Guercini, S. (2020), "Pharmaceutical industry riding the wave of sustainability: review and opportunities for future research", fournal of Cleaner Production, Vol. 261, pp. 1-12.

Munksgaard, K.B. and Ford, D. (2017), "The business actor and business management”, IMP fournal, Vol. 11 No. 2, pp. 327-347.

Nissen, H.A., Evald, M.R. and Clarke, A.H. (2014), "Knowledge sharing in heterogeneous teams through collaboration and cooperation: exemplified through publicprivate-innovation partnerships", Industrial Marketing Management, Vol. 43 No. 3, pp. 473-482.

Oortwijn, W., Determann, D., Schiffers, K., Tan, S.S. and van der Tuin, J. (2017), “Towards integrated health technology assessment for improving decision making in selected countries", Value in Health, Vol. 20 No. 8, pp. 1121-1130.

Oruezabala, G. and Rico, J.C. (2012), "The impact of sustainable public procurement on supplier management the case of French public hospitals", Industrial Marketing Management, Vol. 41 No. 4, pp. 573-580.

Panteli, D., Eckhardt, H., Nolting, A., Busse, R. and Kulig, M. (2015), "From market access to patient access: overview of evidence-based approaches for the reimbursement and pricing of pharmaceuticals in 36 European countries", Health Research Policy and Systems, Vol. 13 No. 1, pp. 1-8.

Rome, B.N. and Avorn, J. (2020), "Drug evaluation during the Covid-19 pandemic", New England fournal of Medicine, Vol. 382 No. 24, pp. 2282-2284.

Schiavone, F. and Simoni, M. (2019), "Strategic marketing approaches for the diffusion of innovation in highly regulated industrial markets: the value of market access", Fournal of Business E Industrial Marketing, Vol. 34 No. 7, pp. 1606-1618.

Sendyona, S., Odeyemi, I. and Maman, K. (2016), "Perceptions and factors affecting pharmaceutical market access: results from a literature review and survey of stakeholders in different settings", Fournal of Market Access $\mathcal{E}$ Health Policy, Vol. 4 No. 1, p. 31660.

Smyth, H. and Edkins, A. (2007), "Relationship management in the management of PFI/PPP projects in the UK", International Fournal of Project Management, Vol. 25 No. 3, pp. 232-240.

Thilenius, P., Pahlberg, C. and Havila, V. (2016), Extending the Business Network Approach: New Territories, New Technologies, New Terms, Palgrave Macmillan.

Toole, A.A. (2012), "The impact of public basic research on industrial innovation: evidence from the pharmaceutical industry", Research Policy, Vol. 41 No. 1, pp. 1-12.

Wagrell, S. and Baraldi, E. (2019), "The joys and sorrows of a start-up's interactions with the public sphere: a case from 
medical technology", Fournal of Business $\mathcal{E}$ Industrial Marketing, Vol. 34 No. 1, pp. 267-283.

Waluszewski, A. (2011), "Rethinking innovation policy", IMP Fournal, Vol. 5 No. 3, pp. 140-156.

Welch, C. and Wilkinson, I. (2004), "The political embeddedness of international business network", International Marketing Review, Vol. 21 No. 2, pp. 216-231.

Zannad, F., Garcia, M.D.L.A.A., Borer, J.S., Stough, W.G., Clutton-Brock, T., Rosenberg, Y. and Packer, M. (2017),
"Role of payers in the development of cardiovascular therapeutics: misalignment between approval and reimbursement", Fournal of the American College of Cardiology, Vol. 70 No. 22, pp. 2822-2830.

\section{Corresponding author}

Matilde Milanesi can be contacted at: matilde.milanesi@ unifi.it

For instructions on how to order reprints of this article, please visit our website:

www.emeraldgrouppublishing.com/licensing/reprints.htm

Or contact us for further details: permissions@emeraldinsight.com 